\title{
Analysis of the South Atlantic Magnetic Anomaly Behavior Based on Historical Data from the IGRF and GUFM1 Models in the 1590-2021 Interval
}

\author{
Laisa Prata Moreira Fernandes \\ Scientific Initiation Student, \\ Instituto Nossa Senhora da Glória, \\ Macaé, Rio de Janeiro, Brazil
}

\author{
Yasmim Vilela Fraga Vieira \\ Scientific Initiation Student, \\ Instituto Nossa Senhora da Glória, \\ Macaé, Rio de Janeiro, Brazil
}

\author{
João Victor Jobim de Souza e Silva \\ Scientific Initiation Student, \\ Instituto Nossa Senhora da Glória, \\ Macaé, Rio de Janeiro, Brazil
}

\author{
*Hans Schmidt Santos \\ Full Professor, \\ Faculdade Católica Salesiana de Macaé, \\ Macaé, Rio de Janeiro, Brazil \\ (hans.schmidt@live.com)
}

\author{
Vânia Regina de Oliveira Branco \\ Full Professor, \\ Instituto Nossa Senhora da Glória, \\ Macaé, Rio de Janeiro, Brazil
}

\begin{abstract}
This work presents the analysis of the South Atlantic Magnetic Anomaly (SAMA) based on historical data of the total magnetic field in the interval 1590-2021. The study is carried out in a quadrant with longitude ranging from -90 degrees to +60 degrees and latitude ranging from -60 degrees to +30 degrees with points collected every 5 degrees, using the IGRF and Gufm1 models. Data processing is performed in the Oasis Montaj software through minimum curvature interpolation, it generating six maps of the Earth's geomagnetic field. The maps show the SAMA displacement south-west from Africa towards South America, moving 7,860 km between 1590 and 2021 with an average rate of $18 \mathrm{~km} /$ year of advance.
\end{abstract}

\section{Keywords}

South Atlantic Magnetic Anomaly; IGRF; Gufm1.

\section{INTRODUCTION}

The Earth's magnetic field is known to be strongest near the poles. However, there are areas on Earth with lower magnetic field strength and that are constantly weakening, not showing to be stationary over the years. There is, therefore, a scientific name for this phenomenon, the South Atlantic Magnetic Anomaly (SAMA), which has an extensive area of around 4.8 million square kilometers. The emergence of SAMA is intrinsically related to the movements of the conducting fluid in the Earth's outer core. Thus, SAMA may have its origin from a reverse magnetic flux at that interface, in a region below South America and South Africa, where its existence has been noted for the last 200 years [1].

Currently, SAMA has an elongated shape, extending from South America to Africa, and its center (due to the minimum intensity) for the year 2015, located in Paraguay [2].

In recent centuries, SAMA has continually drifted westward. The general behavior of SAMA indicates that it may be related to the asymmetry between the Northern and Southern hemispheres of the geomagnetic field. This asymmetry would be connected to a general drop in the dipole field and a significant increase in the non-dipolar field in the South Atlantic [3].

The magnetosphere protects our planet from electrically charged particles from space, deflecting them across field lines. As SAMA has low total magnetic field strength, this region offers less resistance to particle flow. Thus, it is observed that the region affected by SAMA presents several phenomena produced by the interaction of the particle flux with the field lines, some of which cause problems in equipment and satellites that orbit the Earth. An important example is the increase in cosmic particle radiation, due to the distortion of the Van Allen belt, which affects satellites that pass through this area [4].

Thus, the study of the South Atlantic Magnetic Anomaly is certainly important, as SAMA represents a constant warning signal for the electronic instruments of aircraft and space vehicles that fly over it and for those who reside in its coverage region. As it is a region of lower field strength, it offers less resistance to the entry of cosmic particles. An example of this was NASA's announcement of a temporary failure in the Hubble Telescope's onboard memory as it passed through SAMA [5].

Thus, this paper uses historical data from the Earth's Magnetic Field (CMT) from the geomagnetic models IGRF and Gufm1 to analyze the displacement of SAMA across the southern hemisphere over the past few centuries. For that, in section II the materials and methods will be presented, in section III the main results will be presented and discussed through the analysis of the maps. Finally, in section IV, the main final considerations will be presented.

\section{MATERIALS AND METHODS}

Using data from the Earth's magnetic field, historical data from the IGRF-12 and Gufm1 models referring to the Total Field were processed. Data were collected in a quadrant with longitude ranging from -90 degrees to +60 degrees and latitude ranging from -60 degrees to +30 degrees with points collected every 5 
degrees. These full magnetic field data were obtained from the NOAA (National Oceanic and Atmospheric Administration) website https://www.ngdc.noaa.gov/geomag/calculators/magcalc.shtml?us eFullSite=true\#igrfwmm with the Estimated Magnetic Field Values tool (Figure 1):

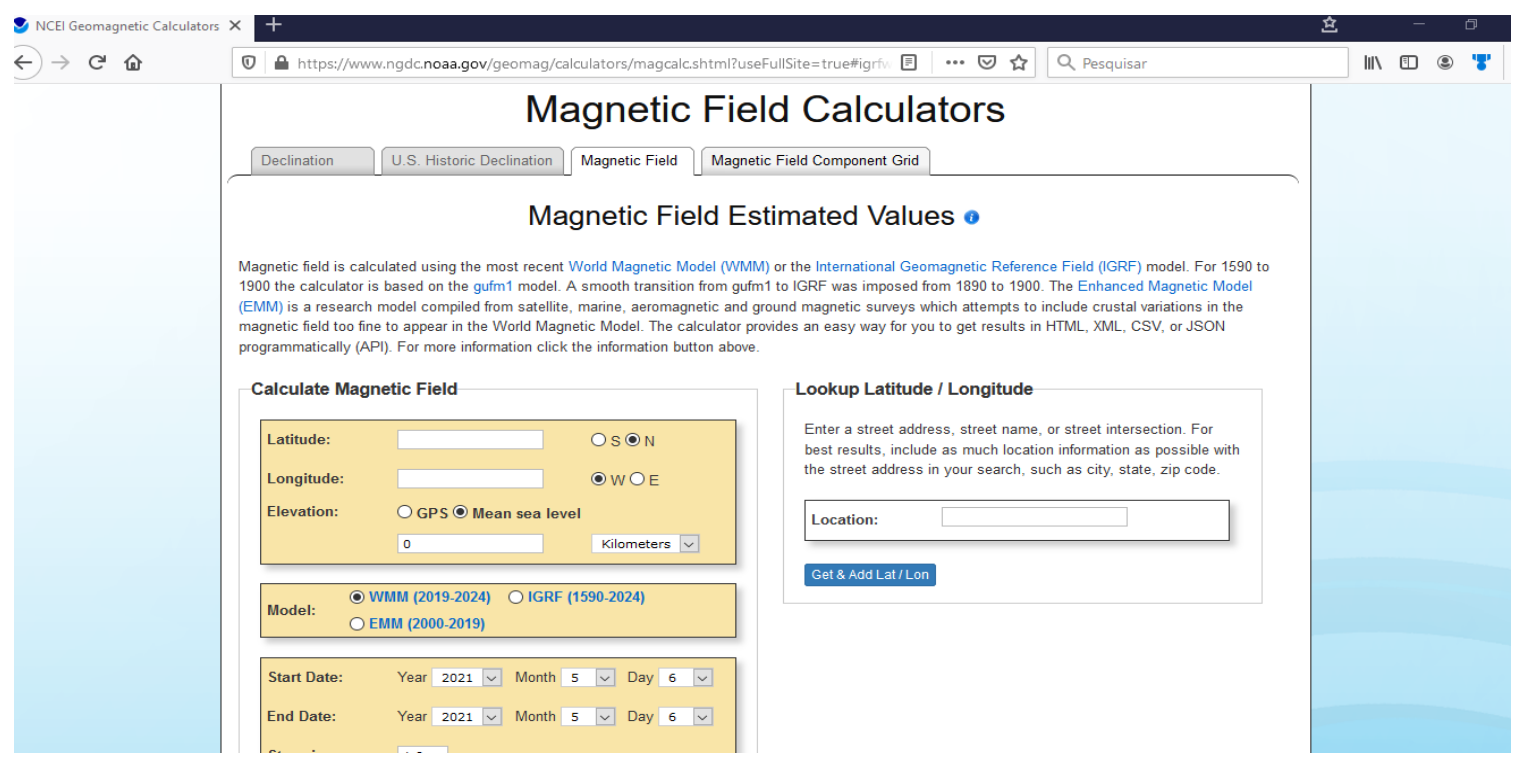

Figure 1: IGRF-12 and Gufm1 data provided by NOAA website

After data acquisition, the data were processed using Geosoft's

Oasis Montaj software (Figure 2).

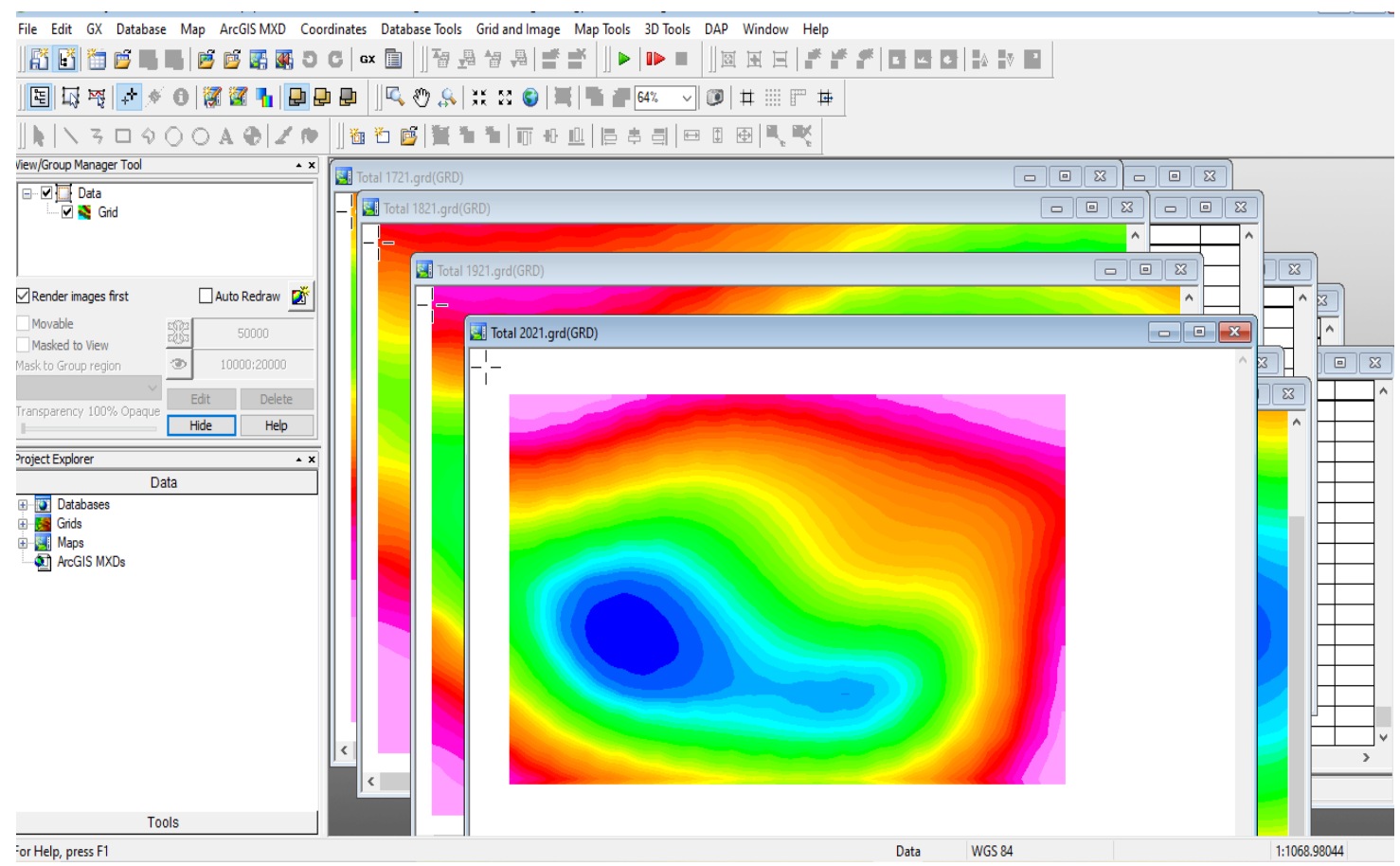

Figure 2: Oasis Montaj software working screen

The total geomagnetic field data were interpolated by the Minimum Curvature Method with 1/4 cells of data resolution, that is, 1.25 degrees. From the 6 grids, 6 bidimensional maps of Total
Field from the years 1590,1621,1721, 1821, 1921 and 2021 were constructed with the way of perceiving the displacement of the 
South Atlantic Magnetic Anomaly between Africa and South America.
The contours of the African and South American continents were extracted using the Graph Digitizer software as shown in Figure 3.
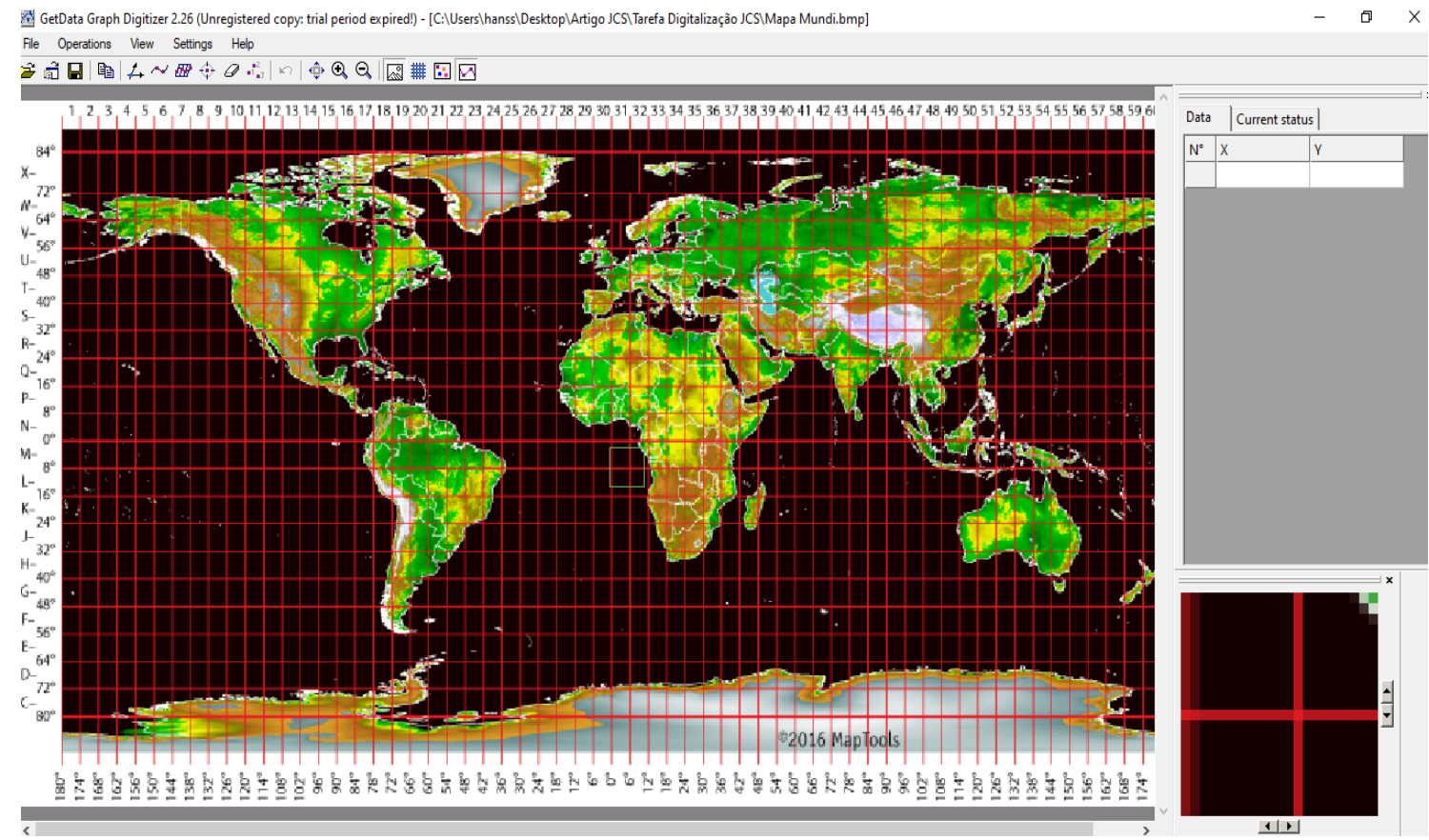

Figure 3: Work screen of the graph digitizer software

In possession of the contours of the continents, they were specified as a .ply extension in the Oasis Montaj program, allowing the location of South America and Africa on the maps made as shown in Figure 4.

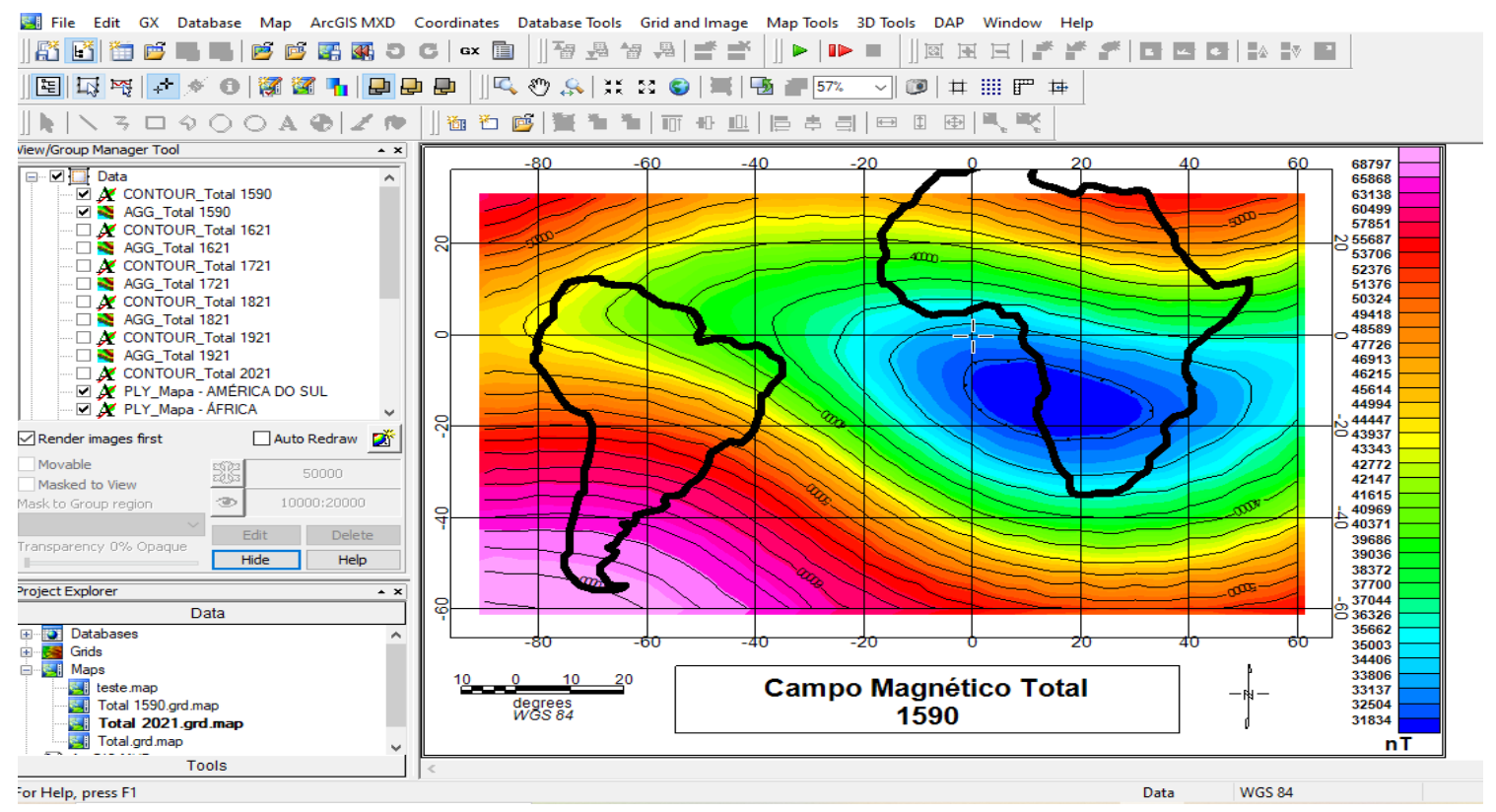

Figure 4: South American and African contours in the Oasis Montaj program 
After making the maps, the six depocenters of the South Atlantic Magnetic Anomaly in the years 1590, 1621, 1721, 1821, 1921 and 2021 were identified. In possession of the position of the depocenters, the distances between them were calculated using a geographical calculator by the INPE. (National Institute for Space Research) available at: http://www.dpi.inpe.br/calcula/ as shown in Figure 5.

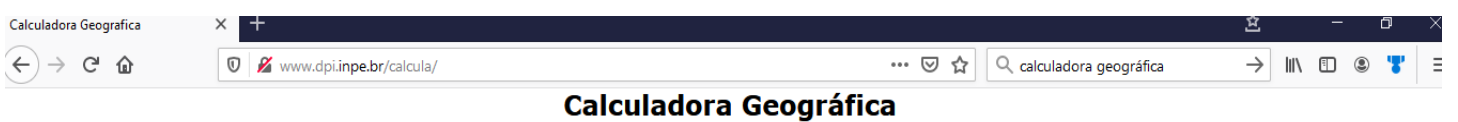

Calculadora Geográfica

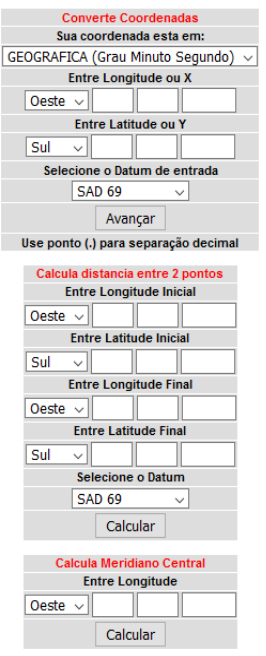

Figura 5: Geographical calculator provided by INPE

Finally, with the maps made and the distances between the depocenters of the South Atlantic Magnetic Anomaly calculated, the interpretation of the data presented in the next chapter was carried out.

\section{DATA ANALYSIS}

Data processing generated six images that describe the position and intensity of the South Atlantic Magnetic Anomaly from 1590 to 2021 (Figures 6, 7, 8, 9, 10 and 11).

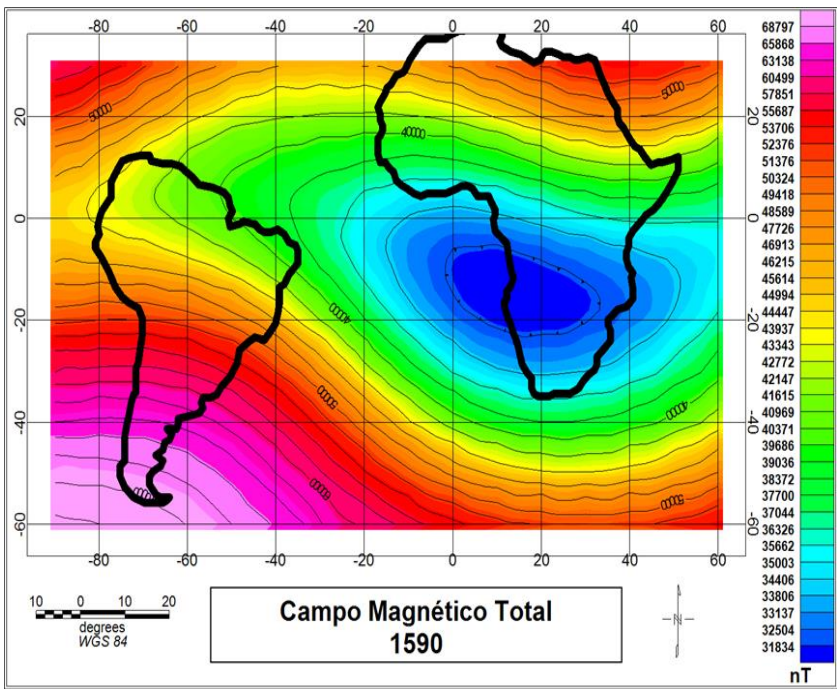

Figure 6: Status of the total magnetic field in the year 1590

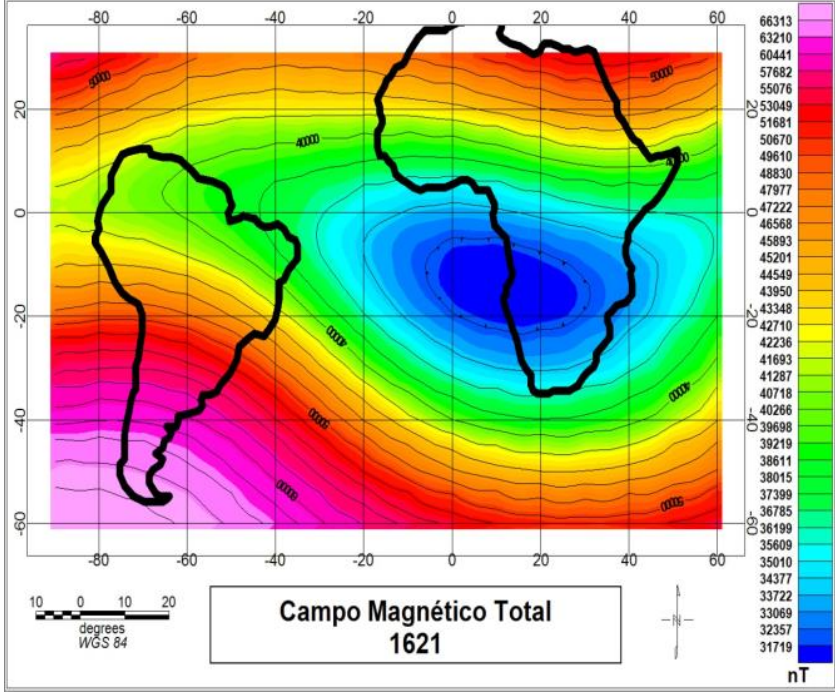

Figure 7: Status of the total magnetic field in the year 1621 


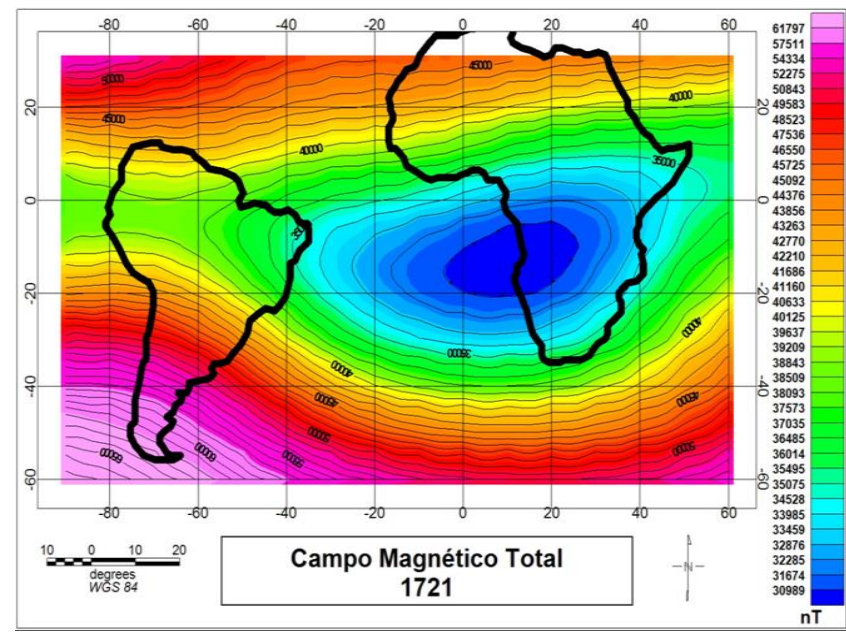

Figure 8: Status of the total magnetic field in the year 1721

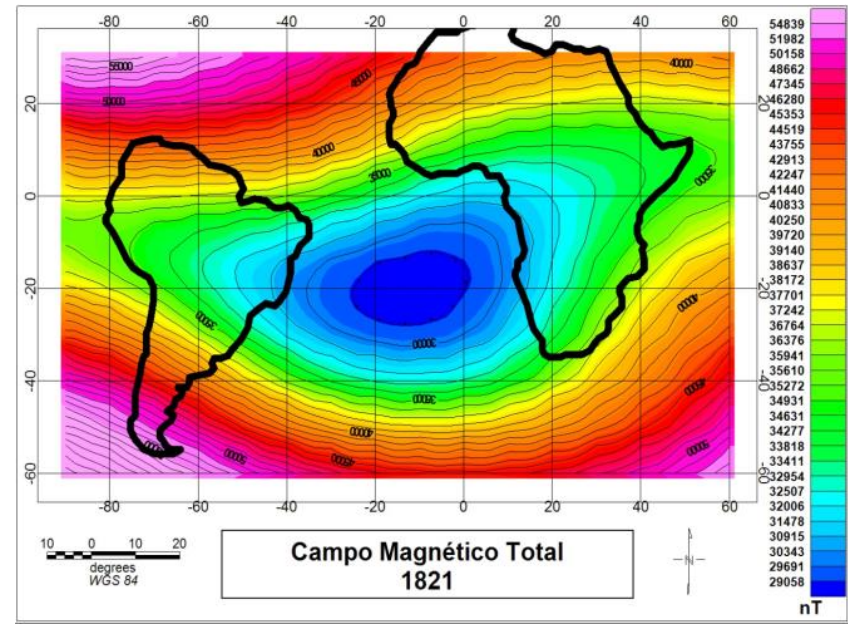

Figure 9: Status of the total magnetic field in the year 1821

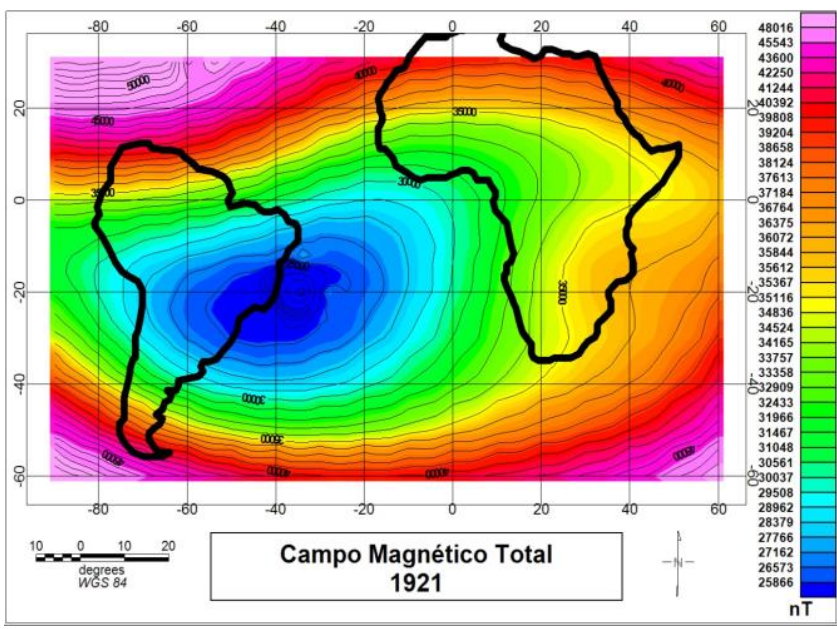

Figure 10: Status of the total magnetic field in the year 1921

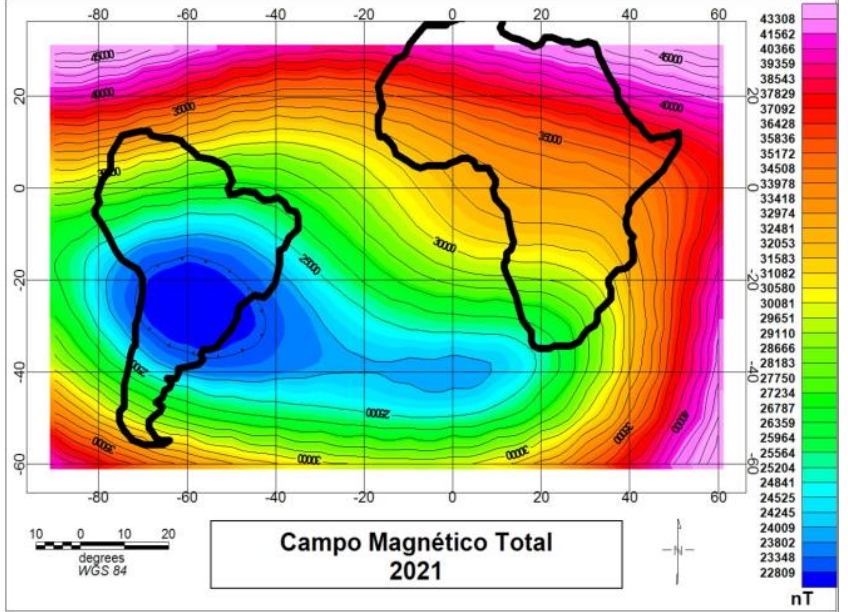

Figure 1: Status of the total magnetic field in the year 2021

A general analysis of the figures shows the displacement of the South Atlantic Magnetic Anomaly towards the southwest, it leaving Africa towards South America over the centuries. Thus, a total displacement of the magnetic field depocenter of 7,860 km between 1590 and 2021 was verified, with an advance of 18 $\mathrm{km} / \mathrm{year}$ on average. Through the figures it is possible to analyze the South Atlantic Magnetic Anomaly through the five time intervals between 1590 and 2021: I. In 1590-1621, the center of the anomaly shifted $385 \mathrm{~km}$ to the west at an average rate of 12 $\mathrm{km} /$ year and the intensity went from $31,834 \mathrm{nT}$ to $31,719 \mathrm{nT}$, thus presenting a drop of $115 \mathrm{nT}$ with a weakening of $-4 \mathrm{nT} / \mathrm{year}$. During this period there was no significant change in the shape of the anomaly. II. In 1621-1721, the center of the anomaly shifted $70 \mathrm{~km}$ to the southwest at an average rate of $1 \mathrm{~km} /$ year and the intensity went from $31,719 \mathrm{nT}$ to $30,989 \mathrm{nT}$, thus showing a drop of $730 \mathrm{nT}$ with a weakening of $-7 \mathrm{nT} / \mathrm{year}$. Thus, it was verified that the center of the SAMA hardly moved, however, there was a change in the shape of the anomaly, which previously had an inclination from northwest to southeast in 1621, remaining with an inclination from northeast to southwest in 1721. III. In 17211821 , the center of the anomaly shifted $2,521 \mathrm{~km}$ to the southwest with an average rate of $25 \mathrm{~km} /$ year and the intensity went from $30,989 \mathrm{nT}$ to $29,058 \mathrm{nT}$, thus showing a drop of $1,931 \mathrm{nT}$ with a weakening of -19 nT/year. In this interval, there was an acceleration of the weakening of AMAS in relation to the previous period, as the rate changed from $-7 \mathrm{nT} /$ year to $19 \mathrm{nT} / \mathrm{year}$ and as to the format there were no significant changes. IV. In 1821-1921, the center of the anomaly shifted 23,127 km to the southwest with an average rate of $31 \mathrm{~km} /$ year and the intensity went from $29,058 \mathrm{nT}$ to $25,866 \mathrm{nT}$, thus presenting a drop of $3,192 \mathrm{nT}$ with a weakening of $-32 \mathrm{nT} /$ year. The greatest displacement was observed, with a speed of $31 \mathrm{~km} / \mathrm{year}$, in relation to the other intervals, as well as the largest drop, with -32 nT/year, it showing again an acceleration of its weakening and regarding its shape, it maintained if similar. V. In the fifth and last period analyzed 1921-2021, the center of the anomaly shifted $1,757 \mathrm{~km}$ to the northwest with an average rate of $18 \mathrm{~km} /$ year and the intensity went from $25,866 \mathrm{nT}$ to $22,809 \mathrm{nT}$, thus presenting a drop of 3,057 nT with weakening of $-31 \mathrm{nT} /$ year. The interval in question showed an intermediate displacement and a small 
deceleration of the weakening rate, which was $-32 \mathrm{nT} / \mathrm{year}$ in the previous period, it getting $-31 \mathrm{nT} / \mathrm{year}$. The anomaly reached its lowest value in the year 2021, reaching $22,809 \mathrm{nT}$. In relation to its shape, there was a change of inclination, which returned to its initial state of 1590 (northwest-southeast). Furthermore, a possible division of the South Atlantic Magnetic Anomaly into two depocenters was noted, where the one located to the west has an intensity of about $23,000 \mathrm{nT}$ and the other depocenter to the east with an intensity of about $24,000 \mathrm{nT}$.

\section{CONCLUSION}

In the present work, the South Atlantic Magnetic Anomaly was described and analyzed by means of historical data from the IGRF and Gufm1 models, from the year 1590 to the current year. The analysis of the maps allowed us to visualize the displacement of the anomaly in the Atlantic Ocean, it leaving Africa towards South America. In addition, displacement rates and annual variations in the anomaly intensity were calculated, it showing that it weakened in all periods studied. Analyzing the intervals, the largest displacement of the South Atlantic Magnetic Anomaly was observed in the interval 1821-1921, in which there was a displacement of $23,127 \mathrm{~km}$. Furthermore, the greatest drop in magnetic field intensity in this same time interval was found, with a value of 3,192 nT. A suggestion for future work, a mapping of the total magnetic field of the entire globe may be carried out, as this will allow evaluating the behavior of the South Atlantic Magnetic Anomaly on a smaller scale. It is also suggested to analyze the $\mathrm{X}, \mathrm{Y}$ and $\mathrm{Z}$ components of the total magnetic field in the same intervals studied in this work, as it will enable the analysis of the contributions of each component in the observed variations.

\section{REFERENCES}

[1] GUBBINS, D.; HERRERO-BERVERA, E.. Encycopledia of Geomagnetism and paleomagnestism. Springer, ISBN 978-14020-4423-6, Dondrecht, The Netherlands, 2007.Ding, W. and Marchionini, G. 1997. A Study on Video Browsing Strategies. Technical Report. University of Maryland at College Park.

[2] HARTMANN, G.A.. The South Atlantic Magnetic Anomaly: Causes and Effects. Dissertation (Masters in Geophysics) Institute of Astronomy, Geophysics and Atmospheric Sciences, University of São Paulo, São Paulo, 2005.Tavel, P. 2007. Modeling and Simulation Den. AK Peters Ltd., Natick, MA.

[3] MORO, J.; JASKULSKI, T.; MURALIKRISHNA, P.; NARDIN, C.M.; SCHUCH, N.J.. Ionospheric Plasma Studies in the Geomagnetic Anomaly Region ofForman, G. 2003. An extensive empirical study of feature selection metrics for text classification. J. Mach. Learn. Res. 3 (Mar. 2003), 1289-1305. South Atlantic. Final Report of Scientific Initiation Project PIBIC/INPE CNPQ/MCT, 2007.

[4] HEIRTZLER, J.R. The Future of the South Atlantic Anomaly and implications for radiation damage in space. Journal of Atmospheric and Solar-Terrestrial Physics, 64, 1701-1708, 2002.Yu, Y. T. and Lau, M. F. 2006. A comparison of MC/DC, MUMCUT and several other coverage criteria for logical decisions. J. Syst. Softw. 79, 5 (May. 2006), 577-590. DOI= http://dx.doi.org/10.1016/j.jss.2005.05.030. 